\title{
MÜFREDAT BAZLI AKADEMİK ZAMAN ÇİZELGELEME PROBLEMİNİN ÇÖZÜMÜNE TAM SAYILI DOĞRUSAL PROGRAMLAMA YAKLAŞIMI
}

\author{
Yunus DEMIR, Cafer ÇELIKK \\ Atatürk Üniversitesi, Endüstri Mühendisliği Bölümü, Erzurum \\ demiry@atauni.edu.tr, ccelik@atauni.edu.tr
}

(Geliş/Received: 06.01.2015; Kabul/Accepted: 31.12.2015)

\section{ÖZET}

\begin{abstract}
Akademik zaman çizelgeleme problemleri, polinom zamanda çözülemeyen NP-Zor olarak nitelendirilen optimizasyon problemleri sınıfına girmektedir. Yöneylem araştırması literatüründe bu problemlerin; kayıt bazlı zaman çizelgeleme ve müfredat bazlı zaman çizelgeleme olmak üzere iki ana başlık altında incelendiği görülmektedir. Bu çalışmada müfredat bazlı akademik zaman çizelgeleme alanında yapılmış çalışmalar kapsamlı bir şekilde ele alındıktan sonra Atatürk Üniversitesi Mühendislik Fakültesi ders çizelgeleme süreci analiz edilmiştir. Ele alınan problem, diğer birçok çalışmada olduğu gibi yalın bir ders atama problemi olmayıp, derslerin ait oldukları bölüm ve sınıflara (öğrenci gruplarına) ait birçok kısıtı içermektedir. Öğretim üyelerinin unvanlarına göre ders programından memnuniyetlerinin enbüyüklenmeye çalışılldığı bu problem için tam sayılı doğrusal bir model önerilmiş ve küçük boyutlu bir örnek için önerilen model çözülerek sonuçlar değerlendirilmiştir.
\end{abstract}

Anahtar Kelimeler: Akademik zaman çizelgeleme problemi, tam sayılı doğrusal programlama

\section{AN INTEGER PROGRAMMING APPROACH FOR CURRICULUM BASED TIMETABLING PROBLEM SOLUTION}

\begin{abstract}
Academic timetabling problems a class of NP-Hard type problem which cannot be solved in polynomial time. In literature, these problems are studied under two different main topics which are curriculum and post-enrollment based timetabling problems. In this paper, curriculum based timetabling problem is entirely reviewed then timetabling procedure of Atatürk University Engineering Faculty is analyzed. The problem which is handled in this paper is not only a lean lecture assigning problem but also including several constraints related to lecture given departments and classes (student groups). In this study an integer linear model is proposed to maximize the satisfaction of teaching staff from timetable according to their appellation and numerical results, obtained from solution of a small sized sample, are evaluated.
\end{abstract}

Keywords: Academic timetabling problem, integer linear programming

\section{GIRIŞ (INTRODUCTION)}

Akademik zaman çizelgeleme problemi (AZÇP), hem araştırmacılar hem de uygulayıcılar tarafindan yoğun bir şekilde çalışılmakta olan bir alandır. AZÇP genel manada; seçmeli-zorunlu, tek-çok gruplu gibi bir takım özelliklere sahip derslerin belirli kısttlar altında sınırlı sayıdaki zaman dilimlerine ve dersliklere atanması şeklinde tanımlanabilir. Üniversite yönetimleri, her dönem çözülmesi gereken bu problem için büyük insan kaynağı ile uzun zamanlar harcamaktadır. Problem, belirli amaçlar ve durumlarla ilişkili çok sayıda öğrenci, eğitmen, ders ve derslik gibi bileşenleri içerdiğinden, çözümü için geliştirilen süreçler çok sayıda kısıt ve değişkeni dikkate almak zorundadır. Genel olarak NP-Zor olduğu ispatlanan [1] bu problemin yapisı akademik sistemlerdeki çeşitlilikten dolayı ülkeden ülkeye, hatta aynı ülkenin akademik sistemi içerisindeki üniversitelerde bile farklılık göstermektedir. Bu sebeplerden dolayı AZÇP 
yöneylem araştırması literatüründe 25 yıldır yoğun bir şekilde çalışılmakta ve halen popülaritesini korumaktadır [2]. Literatürde genel olarak AZÇP'ler iki ana başlık altında incelenmektedir. ITC 2002 ve ITC $2007^{1}$ uluslararası zaman çizelgeleme yarışmalarına konu olan problem tiplerinden birincisi, kayıt bazlı zaman çizelgeleme problemi (KBZÇP) [38], diğeri ise müfredat bazlı zaman çizelgeleme problemidir (MBZÇP). Birinci kategoride öğrencilerin devam etmek istedikleri dersleri seçme hakkı vardır ve zaman çizelgeleme, öğrencilerin devam etmek istedikleri dersleri seçtikten sonra yapılır. Diğer kategoride ise zaman çizelgeleme, önceden belirlenmiş periyot ve derslik sayıları ile yine önceden planlanmış haftalık derslere göre yapılır. Diğer bir deyişle zaman çizelgesi, gelen kayıt bilgisine göre değil, üniversite yönetimi tarafindan belirlenmiş müfredata göre yapılır [9]. Bu iki problem tipi arasındaki en önemli farklılık; kısıtlar ve amaç fonksiyonunun MBZÇP'de müfredata göre, KBZÇP'de kayıt olan öğrencilere göre şekillendirilmesidir [10]. Bu çalışmada, MBZÇP'ye odaklanılmıștır. İkinci bölümde, önce Gaspero ve arkadaşları [11] tarafindan tanımlanan ve Uluslararası Zaman Çizelgeleme Yarışmasında (ITC 2007) kullanılan en genel versiyonu tanıtılmış, daha sonra literatürde yer alan diğer versiyonları incelenmiştir. Üçüncü bölümde problemin anlaşılabilirliğini artırmak üzere önce modelde kullanılan notasyonlara yer verilmiş ve problemle ilgili genel kavramlar tanıtılmış, daha sonra üzerinde çalışılan problem detaylı bir şekilde açıklanmıştır. Dördüncü bölümde, problemin tam sayılı doğrusal modeli sunulmuştur. Beşinci bölümde modeldeki doğrusal olmayan kısıtların doğrusallaştırılmasından bahsedilmiştir. Altıncı bölümde, geliştirilen model küçük boyutlu bir problem için çözülmüştür. Yedinci bölümde modelin çözümüyle ulaşılan sayısal sonuçlar tartışılmıştır. Son bölümde ise makale genel olarak değerlendirilerek önerilere yer verilmiştir.

\section{MÜFREDAT \\ BAZLI ÇIZELGELEME (CURRICULUM \\ ZAMAN TIMETABLING)}

Günümüze kadar araştırmacılar tarafindan birçok MBZÇP tanımlanmıştır. Bu bölümde öncelikle, 2007 yılında AZÇP alanında düzenlenmiş ITC 2007 uluslararası zaman çizelgeleme yarışmasında tanımlanan en genel MBZÇP sunulmuş, daha sonra diğer versiyonları incelenmiştir [11].

2.1 MBZÇP'nin Genel Tanımı (Common Definition of Curriculum Based Timetabling Problem)

Bu problem, AZÇP'nin literatürde çokça çalışılmış bir versiyonudur. Di Gaspero ve Schaerf [12] tarafindan 2003 yılında tanıtılmıs probleme esnek kısıtlardan

1

http://www.cs.qub.ac.uk/itc2007/index_files/competit iontracks.htm olan derslik tutarlılığı kısıtının ilave edilmiş halidir. $\mathrm{Bu}$ yarışmada katılımcılara sunulan problem; verilen her dersin her oturumunun haftalık ders çizelgesine, verilen kısıtlar çerçevesinde atanmasıdır [11]. Veri seti İtalya Udine Üniversitesi'nden alındığı için Udine ders çizelgeleme problemi olarak da adlandırılan bu problemde kisitlar, olmazsa olmaz kisitlar anlamında zorunlu kisitlar ve sapmaları ifade eden esnek kısitlar olmak üzere ikiye ayrılmıştır. Aşağıda verilen dört zorunlu (Z1-Z4) ve dört esnek kisıt (E1-E4) setleri altında araştırmacılar, oluşturulan uygun çözümde esnek kisitlarda meydana gelen ihlallerin enküçüklenmesini hedeflemişlerdir [13-18].

\section{Zorunlu Kisıtlar:}

Z1. Dersler: Bütün dersler haftalık ders programına en fazla bir dersliğe olacak şekilde atanmalıdır.

Z2. Derslik Doluluğu: Her hangi iki dersin oturumları, aynı anda aynı dersliğe atanamaz.

Z3. Ders Çakışması: Aynı müfredat içerisindeki (aynı sınıftaki) derslerin oturumları veya aynı öğretim üyesi tarafindan verilen derslerin oturumları haftalık ders programında aynı periyoda atanamaz. Yani, hiçbir periyotta ne öğrenciler ne de öğretim üyeleri açısından çakışma olamaz.

Z4. Uygun Olma: Dersi verecek öğretim üyesi her hangi sebepten dolayı belirli bir periyot için uygun değilse, o periyota ilgili öğretim üyesinin hiçbir dersi atanamaz.

\section{Esnek Kisıtlar:}

E1. Derslik Kapasitesi: Derslik kapasitesi, derse devam eden öğrenci sayısından küçük olamaz.

E2. Derslik Tutarlılığı: Bir dersin bütün oturumları aynı dersliğe atanmalıdır. Eğer bu mümkün değilse ilgili derse atanan derslik sayısı en az tutulmalıdır.

E3. Minimum Çalışma Günü: Bir dersin oturumları haftalık ders programı içerisine önceden verilen minimum gün sayısı kadar dağıtılmalıdır.

E4. Müfredat Yoğunluğu: Bir dersin bir oturumunun atandığı periyodun öncesinde veya sonrasında boş bir periyot varsa, bu ilgili müfredat için bir ihlal sayılır. Yani öğrenciler açısından dersler arası boşluk olmayan bir program hazırlanmak istenmektedir.

\subsection{MBZÇP'nin Diğer Versiyonları (Other Versions} of Curriculum Based Timetabling Problem)

Bir önceki bölümde uluslararası zaman çizelgeleme yarışmasında (ITC 2007) kullanılan Di Gaspero ve arkadaşları [11] tarafindan oluşturulmuş MBZÇP'den bahsedilmiştir. $\mathrm{Bu}$ formülasyonun dışında MBZÇP'nin literatürde birçok versiyonu bulunmaktadır. Partida ve arkadaşları [19] tarafindan Meksika'da UPAEP Üniversitesi için yapılan çalışmada bazı dersler için haftalık zaman çizelgesinde tüm periyotlara değil de, tanımlanmış belirli zaman aralıklarına atanması zorunluluğu getirilmiştir. Problemin çözümü için matematiksel 
model önerilen bu çalışmanın amacı ise zaman çizelgesine atanan derslerin enbüyüklenmesi olarak benimsenmiştir. Bakır ve Aksop [20], Gazi Üniversitesi İstatistik Bölümünde yaptıkları çalışmada, amaç fonksiyonunu öğrencilerin ve öğretim üyelerinin memnuniyetsizliklerinin enküçüklenmesi olarak belirlemişlerdir. İlgili bölümde bazı dersler pratik ve teorik olarak iki kısımdan oluşmaktadır. Yönetim, teorik kısmın pratikten önce yapılmasını istemektedir. Bölümde dersler örgün ve ikinci öğretim olmak üzere iki grup halinde yapılmaktadır. Yazarlar çalışmada, ilgili fakültenin öğretim üyeleri tarafindan verilmeyen örgün öğretimdeki dersler ile ikinci öğretimdeki derslerin zamanları arasının en az tutulmasını hedeflemişlerdir. Böylelikle fakülteler arası mesafeler uzun olduğundan fakülte dışı öğretim üyeleri fakülteden ayrılmadan ve fakültede çok beklemeden derslerini vermeleri amaçlanmıştır. Ayrıca bu çalışmada bir ders, alttan alan öğrenciler için, bir sonraki sınıfin dersi ile mümkün olduğunca çakıştırılmamaya çalışılmıştır. Cura [21], çalışmasını İstanbul Üniversitesi İşletme Fakültesi'nde gerçekleştirmiştir. $\mathrm{Bu}$ çalışmayı diğer çalışmalardan ayıran en önemli özellik, öğretim üyelerinin kıdem durumunu dikkate alarak tatmin düzeyinin enbüyüklenmesini amaçlamasıdır. Bir diğer farklı kısıt ise haftalık zaman çizelgesinde her günün en az yarısının derslerle dolu olmasıdır. Al-Yakoob ve Sherali [22], Kuveyt Üniversitesi'nde gerçekleştirdikleri çalışmada; çok fazla etkileşimli kısıtları barındırmayan, cinsiyet ayrımını dikkate alan (bay-bayan ve karma sınıflar şeklinde) verimli derslik çizelgelemesi problemini ele almışlardır. Çalışmada, zaman çizelgesinin her bir periyodunda eğitim görecek öğrenci sayısına alt ve üst sınır getirilerek derslerin haftaya yayılması sağlanmış ve bu şekilde park alanında oluşacak trafik yoğunluğunun azaltılması amaçlanmıștır. Dimopoulou ve Miliotis [23] Atina Ekonomi ve İşletme Üniversitesi'nde yaptıkları çalışmada, bir problemin birden fazla parçaya bölünüp, her bir parçanın farklı bir bilgisayar tarafindan çözdürüldüğü dağıtık hesaplama tekniği kullanmışlardır. Çözüm yaklaşımları üç aşamalı bir yapıdan oluşmaktadır. Önce tüm bölümler tarafından alınan fakülte ortak dersleri çizelgelenmekte, sonra dersleri ayrı ayrı çizelgelemek yerine belirli derslerin toplamını ifade eden ders grupları (bölümler) çizelgelenmektedir. Son olarak ders grupları (bölümler) içerisinde oluşan çakışmalar tekrar ele alınmaktadır. Yazarlar bu çalışmada öğretim üyelerinin memnuniyet düzeyini enbüyüklemeye çalışmışlardır. Daskalaki ve arkadaşları [24] Yunanistan Patras Üniversitesi, Elektrik ve Bilgisayar Mühendisliği Bölümü'nde yaptıkları çalışmada öğretim üyeleri, derslerini vermek istediği gün ve zaman dilimlerini seçebilmek ve bu dersleri tek veya çok oturumda yapabilmek gibi esnekliğe sahiptirler. $\mathrm{Bu}$ çalışmada dikkat çeken bir başka farklı kısıt ise, amfilerde işlenecek dersler arka arkaya atanarak, derslik değişimlerinin enküçüklenmeye çalışılmasıdır. Ayrıca bazı derslerin hangi gün ve hangi zaman dilimine atanacağı önceden bilinmekte (preassignment), probleme parametre olarak girilmektedir. Çalışmada, öğrencilerin zaman çizelgelerinin gün içerisinde mümkün olduğunca toplu olması ve öğrencilerin rahat dinlenebilmesi için öğle saati civarlarının mümkün olduğunca boşaltılması hedeflenmiştir. Literatürdeki MBZÇP'lerde genel olarak hangi dersin hangi öğretim üyesi tarafindan verildiği önceden bilinmektedir. Ancak bazı çalışmalarda bu durum probleme karar değişkeni olarak girmiştir. Gunawan ve arkadaşlarının [25] Endonezya'da bir üniversitede gerçekleştirdikleri çalışmada öğretim üyelerinin derslere atanmasını ve derslerin çizelgelenmesini beraber yapacak tam sayılı bir model ve hibrit bir algoritma önermişlerdir. Tümüklü [26] yüksek lisans tezinde, Bozok Üniversitesi İktisadi ve İdari Bilimler Fakültesi için sınırlı sayıda kısıta sahip olan bir zaman çizelgeleme problemini kısıt programlama şeklinde ele almıştır. Çözüm için, matematiksel model geliştirmiş ve ayrıca bir de genetik algoritma yaklaşımı sunmuştur. Gülcü [27] yüksek lisans tezinde, katı ve esnek kısıtlardan oluşan sekiz kısıtın sapmalarının enküçüklenmesini amaçlayan çalışmasında genetik ve tabu arama algoritmalarını kullanmış ve sonuçları karşılaştırmalı olarak değerlendirmiştir. Basir ve arkadaşları [28], Malezya Sains Islam Üniversitesi Teknoloji Fakültesi bir yıl süreli hazırlık programı için, öğretim elemanlarının ve derslerin çakışmayacağı sade bir problemi tavlama benzetimi yaklaşımı ile çözmüşlerdir. Miranda ve arkadaşları [29], Şili Diego Portales Üniversitesi Mühendislik Fakültesi'nde içerisinde tam sayılı bir model barındıran web tabanlı karar destek sistemi geliştirmişlerdir. Literatürdeki birçok çalışmada derslerin dersliklere ve zaman dilimlerine atanması ayrı ayrı ele alınmakta ve zaman dilimlerine atama belirli kısıtlarla şekillenmektedir.

$\mathrm{Bu}$ çalışmada [29] ise derslerin dersliklere ve zaman dilimlerine aynı anda atanmasını sağlayan ve kalıp (pattern) diye isimlendirilen bir yaklaşım kullanılmıştır. $\mathrm{Bu}$ yaklaşımla yazarlar lineer gevşetmeyi daha sıkı tutup, problemin çözümünü kolaylaştırmayı hedeflemişlerdir. Shiau [30] Tayvan Kun-Shan Üniversitesi'nde yaptığ 1 çalışmada, öğretim üyelerinin ders vermek istedikleri gün ve zaman dilimini, boş bırakmak istedikleri günlerini ve derslerinin oturum sayılarını belirleyebildikleri bir model üzerine çalışmıştır. Yazar, öğretim elemanlarının tercihlerini azami seviyede gerçekleştirecek ve öğrencilerin derslikler arası geçişlerini enazlayacak hibrit bir parçacık sürü algoritması önermiştir. Münih Üniversitesi Bilgisayar Bilimleri Bölümü'nde Abdennadher ve Marte [31] tarafindan yapılan çalışmada göze çarpan kısıtlar şu şekildedir: Pazartesi günü öğleden sonra toplantı olduğundan profesörlere ders atanmamalıdır. Bölüm, 
anabilim dalı diye tabir edebileceğimiz beş alt birime ayrılmıștır. Aynı birimdeki dersler birbiriyle çakışmamalıdır. $\mathrm{Bu}$ çalışmada yazarlar problemi, kısıtların ağırlıklandırıldığı kısıt tatmin problemi şeklinde modellemişlerdir. Almanya Katolik Sosyal Hizmetler Koleji'nde yapılan çalışmada [32], süresine göre 45 ve 90 dakika olmak üzere iki tip ders bulunmaktadır. Kısa dersler arasında 15 dakika, uzun dersler arasında 30 dakika ara verilmektedir. $\mathrm{Bu}$ çalışmada göze çarpan diğer kısıtlar ise şu şekildedir: Dört yıllık eğitim veren programda her sınıf için farklı zamanlarda öğle arası verilmektedir. Bazı dersler arasında öncül ardıl ilişkisi bulunmaktadır. Aynı anda işlenmesi gereken veya farklı günlerde işlenmesi gereken bazı ders kümeleri bulunmaktadır. Okulda görev alan iki öğretim üyesi, sırayla çocuk bakım izni kullandığından, bu iki öğretim üyesine aynı anda ders atanamamaktadır. Problemin çözümü için kısıt programlama yaklaşımı benimsenmiş ve çözümü için Oz kısıt dili kullanılmıştır. Özak ve Saraç'a ait [33], Osmangazi Üniversitesi Endüstri Mühendisliği Bölümü'nde gerçekleştirilen çalışmada seçmeli dersler ve çok gruplu derslerin varlığından bahsedilmiş, ancak bu derslerin aynı gün aynı zaman dilimine atanması zorunlu kılınmıştır. Ayrıca dersler tek oturumda yapılmaktadır. Göze çarpan farklı bir diğer özellik ise öğretim üyelerine ve dördüncü sınıf ögrencilerine programda bir gün boşluk bırakılması zorunluluğudur.

Bu çalışmada ise, Atatürk Üniversitesi Mühendislik Fakültesi zaman çizelgeleme problemi ele alınmıştır. Problemde, öğretim üyelerinin unvan bazlı toplam memnuniyetinin enbüyüklenmesi amaçlanmıştır. Problemin çözümü için tam sayılı doğrusal bir model önerilmiştir.

\section{PROBLEMIN TANIMI (DEFINITION OF THE PROBLEM)}

Problemin anlaşılabilirliğini artırmak üzere önce kullanılan indis ve parametreler verilmiş ve problem içerisinde kullanılan bazı kavramlara açıklık getirilmiştir. Daha sonra ele alınan problem kısıtları ile beraber detaylı bir şekilde açıklanmıştır.

\subsection{Modelde Kullanılan İndis ve Parametreler (Indexes and Parameters Used in The Proposed Model)}

\section{İndisler}

Modelde kullanılan indisler ve anlamları aşağıda verilmiştir:
d, dd: $\quad$ Ders indisi $(d=1,2, \ldots, D)$
g, gg: Gün indisi $(\mathrm{g}=1,2, \ldots, \mathrm{G})$
s, ss: $\quad$ Periyot (saat) indisi $(\mathrm{s}=1,2, \ldots, \mathrm{S})$
$\mathrm{p}$ : $\quad$ Her derse ait oturum indisi $(\mathrm{p}=1,2)$
b: $\quad$ Bölüm indisi $(b=1,2, \ldots, B)$
c: $\quad$ Sinıf indisi $(c=1,2,3,4)$

gn: Grup indisi (çok gruplu verilen derslerde grubun hangi derse ait olduğunu belirlemek için) $(\mathrm{gn}=1,2, \ldots, \mathrm{GN})$

r: $\quad$ Derslik indisi $(r=1,2, \ldots, R)$

$\mathrm{h}$ : $\quad$ Öğretim üyesi indisi $(\mathrm{h}=1,2, \ldots, \mathrm{H})$

\section{Parametreler}

Probleme ait parametreler ve anlamları aşağıda verilmiştir:

$\mathrm{dps}_{\mathrm{dp}}: \quad \mathrm{d}$ dersinin $\mathrm{p}$. oturumunun süresi

$\operatorname{drs}_{\mathrm{d}}: \quad \mathrm{d}$ dersinin yapılabileceği derslik seti

$\mathrm{dr}_{\mathrm{r}}: \quad \mathrm{r}$ dersliğinde yapılabilecek ders seti

$\mathrm{drh}_{\mathrm{d}}$ : $\quad \mathrm{d}$ dersini veren öğretim üyesi

$\mathrm{dh}_{\mathrm{h}}$ : $\quad \mathrm{h}$ öğretim üyesi tarafindan verilen ders seti

$\mathrm{y}_{\mathrm{bc}}$ : $\quad \mathrm{b}$ bölümü, c sınıfina ait ders seti

$\mathrm{dp}_{\mathrm{d}}: \quad \mathrm{d}$ dersinin oturum sayıs

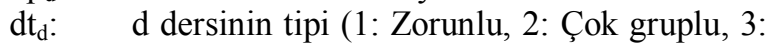
Seçmeli)

$\mathrm{dk}_{\mathrm{d}}$ : $\mathrm{d}$ dersinin katsayısı (1: Seçmeli ve çok gruplu ders, 2: Zorunlu ders)

$\mathrm{dg}_{\mathrm{d}}$ : $\quad$ Çok gruplu d dersine ait grup numarası

unv $_{\mathrm{h}}: \quad \mathrm{h}$ ögretim üyesinin unvan katsayısı

trc $_{\text {hgs }}$ : h öğretim üyesinin g. gün $s$. zaman dilimine ait tercih katsayısı (1-3)

3.2 Problemle İlgili Genel Kavramlar (Common Notions Related with the Problem)

$\mathrm{Bu}$ bölümde problemin ve modelin tanımında sıkça kullanılan kavramlar açıklanmıştır.

Çok gruplu ders: Kayıtlı öğrenci sayısı çok fazla olduğunda birden fazla grup halinde verilen derstir.

Ardıl çakıșma: c. sınıfa ait d dersinin p oturumu g. gün ve s. periyota atanmış olsun. Yine aynı g. gün ve s. periyota, bir üst $(c+1)$ sınıfa ait bir dersin atandığ durumda meydana gelen çakışmadır (Şekil 1a).

Öncül çakıșma: c. sinıfa ait d dersinin p oturumu g. gün ve s. periyota atanmış olsun. Yine aynı g. gün ve s. periyota bir alt (c-1) sınıfa ait bir dersin atandığ durumda meydana gelen çakışmadır (Şekil 1b).

Yan yana çakıșma (YYC)): c. sınıfa ait d dersinin $\mathrm{p}$ oturumunun öncül ve ardıl çakışma sayısıdır. Başka bir deyişle, alt sınıftan ders alan öğrencilerin dersi alabilmesi için fakülte yönetiminin ardışık sınıflardaki derslerin saatlerinin aynı gün ve aynı periyota atanmaması kısıtını ifade eden kavramdır. Şekil 1'de görüldüğü gibi 9 numaralı dersin (c. sinıfa ait ders) birinci oturumu; birinci gün (Pazartesi) ikinci periyotta, iki numaralı dersin (c-1. sinıfa ait ders) birinci oturumu ile bir ders saati (Şekil 1a) ve ikinci gün (Salı) yine dokuz numaralı dersin ikinci oturumu on dört numaralı dersin (c+1. sinıfa ait ders) birinci oturumu ile birinci periyotta bir ders saati (Şekil 1b) olmak üzere iki ders saati yan yana çakışmıştır. 


\begin{tabular}{|c|c|c|c|c|c|}
\hline GÜN & Pryt & I. SINIF & II.SINII & III.Sinff & IV. Sinff \\
\hline \multirow{4}{*}{ 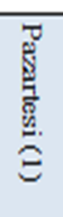 } & 1 & $(2,1)$ & & & \\
\hline & 2 & $(2,1)$ & $(9,1)$ & & \\
\hline & 3 & & $(9,1)$ & & \\
\hline & 4 & & & & \\
\hline
\end{tabular}

a) Ardıl çakışma

\begin{tabular}{|c|c|c|c|c|c|}
\hline & Pryt & I. SINIF & II.SINIF & III.Sinff & IV. Sinif \\
\hline \multirow{4}{*}{ 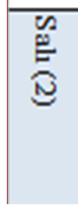 } & 1 & & $(9,2)$ & $(14,1)$ & \\
\hline & 2 & & & $(14,1)$ & \\
\hline & 3 & & & & \\
\hline & 4 & & & & \\
\hline
\end{tabular}

Şekil 1. Öncül ve ardıl çakışmaya bir örnek (A sample for pioneer and successor conflict)

Üst üste çakıșma (ÜÜC): Aynı sınıfa ait iki dersin aynı gün aynı periyotta çakışmasıdır. Bu çalışmada çok gruplu veya seçmeli dersler için en fazla iki ders çakışma olmasına izin verilirken, zorunlu dersler için üst üste çakışmaya izin verilmemiştir.

Bölüm programı: Her bölüme ait haftalık zaman çizelgesidir.

Derslik programı: Dersliklerin kullanım durumunu gösteren çizelgedir.

Öğretim üyesi programı: Öğretim üyelerinin doluluk durumunu gösteren çizelgedir.

\subsection{Problemin Detaylı Tanımı (Detailed Definition of Problem)}

$\mathrm{Bu}$ çalışmada, yaklaşık 5630 öğrencinin öğretim gördüğü Atatürk Üniversitesi Mühendislik Fakültesi için MBZCP ele alınmıștır. Fakülte kapsamında 11 bölüm bulunmakla birlikte, ancak 3 bölüm henüz kuruluş aşamasında olduğundan sadece 8 bölüme öğrenci alınmaktadır. Akademik yıl güz ve bahar yarıyılı olmak üzere ikiye ayrılır ve her dönem için her bölümden gelen koordinatörlerin oluşturduğu bir kurul, fakültenin o dönemki haftalık ders programını oluşturur. Dört yıllık eğitim veren bölümlerde öğrencilere her dönem yaklaşık 7 ders sunulmaktadır. Bir dersten başarısız olan öğrenciler o dersi bir sonraki yıl alttan almak zorundadır. Dersler 2, 3 veya 4 ders saatinden oluşur. Dersler öğretim üyelerinin isteğine göre tek veya birden fazla oturumda verilebilir. Öğrenci sayısı çok olan bazı dersler birden fazla grup halinde yapılabilir. Zorunlu derslerin yanında her bölüm, 3. ve 4. sınıf öğrencilerine seçmeli dersler de sunmaktadır. Zaman çizelgesi hazırlanırken hafta içi her gün 08.00-17.00 saatleri arasında olmak üzere haftalık 45 zaman dilimi kullanılmaktadır. Her ders saati 50 dakika olup 10 dakika ara verilmektedir. Fakülte yönetimi bir dersi, alt sinıftan alan öğrencilerin alabilmesi için, ardıșık sınıflara ait derslerin olabildiğince aynı gün aynı zaman dilimine konulmamasını (yan yana çakışma olmamasını) istemektedir. $\mathrm{Bu}$ çalışmayı, diğer çalışmalardan ayıran en önemli özellik; ayrı ayrı değerlendirilen bölüm ve bu bölümlere ait sinıfların, fakültenin fiziksel yapısı nedeni aynı kaynağı (derslikleri) kullanmasıdır. Unvanlarına göre öğretim üyelerinin memnuniyetini amaç edinen, yani daha yüksek unvana sahip bir öğretim üyesinin daha memnun olmasını hedefleyen bu çalışmadaki varsayımlar ve kısıtlar aşağıda belirtilmiştir:

Varsayımlar:

- Her dersi alan öğrenci sayıları önceden bilinmektedir.

- Hangi dersin hangi öğretim üyesi tarafindan verileceği önceden bilinmektedir.

- Derslik kapasiteleri önceden bilinmektedir.

- Her dersin kaç oturumda yapılacağı ve her oturumun süresi önceden bilinmektedir.

Kısıtlar; derslere, öğretim üyelerine ve dersliklere ilişkin olmak üzere üç alt başlık altında ele alınmıştır.

\section{Derslere İlișkin Kısıtlar:}

- Zaman çizelgesinde aynı bölüm ve sınıfa ait bloğun aynı periyoduna zorunlu derslerden sadece biri atanabilir. Yani zorunlu dersler için ÜÜÇ’ye izin verilmez.

- Seçmeli ve çok gruplu dersler için en fazla iki derse kadar ÜÜÇ'ye izin verilebilir.

- Seçmeli dersler kendi içinde, çok gruplu dersler de kendi içinde üst üste çakışabilir.

- Seçmeli ve çok gruplu dersler tek oturumda verilir.

- Aynı çok gruplu derse ait dersler çeşitliliği artırmak adına üst üste çakışamaz. Örneğin iki grup halinde verilen Kimya ve Fizik derslerini ele alalım. Kimya A grubu, Kimya B grubu ile değil de Fizik A veya $B$ grupları ile üst üste çakışabilir.

- Birden fazla oturumla yapılan derslerin oturumları aynı güne atanamaz.

- Ders oturumları önceden belirlenmiş ders süresi kadar kesintisiz bir şekilde işlenir.

- Müfredattaki bütün dersler zaman çizelgesine atanmalidır.

- Çok gruplu dersler hariç her ders için YYÇ bir ders saatini geçemez. Çok gruplu dersler için YYÇ kısitı ihmal edilir.

\section{Öğretim Üyelerine İliskin Kısıtlar:}

- Bir öğretim üyesi aynı ders saatinde sadece bir derse girebilir.

- Öğretim üyelerinin, ders vermek istedikleri zaman dilimini 1-3 arasında derecelendirerek seçme hakkı bulunmaktadır.

- Öğretim üyelerinin unvanları memnuniyet seviyesini belirleyen amaç fonksiyonu içinde kullanılmaktadır. 


\section{Dersliklere İlișkin Kısıtlar:}

- Bir derslikte aynı ders saatinde en fazla bir ders işlenebilmektedir.

- Bir ders, teknik açıdan uygun (bilgisayar laboratuvarı, teknik resim salonu, ... vb.) ve kapasitesi yeterli bir dersliğe atanabilir.

\section{PROBLEMIN \\ TAM \\ PROGRAMLAMA \\ MODELI \\ PROGRAMMING MODEL OF THE PROBLEM) \\ SAYILI}

Model ile ilgili açıklamalar; karar değişkenleri, kısıtlar ve amaç fonksiyonu olmak üzere 3 alt başlıkta yapılacaktır.

\section{Karar Değisşkenleri}

Probleme ait karar değişkenleri ve anlamları aşağıda verilmiştir:

$$
\mathrm{x}_{\text {bcdpgs }}:\left\{\begin{array}{c}
1, \text { b bölümü c. sınıfa ait olan d dersinin } \mathrm{p} . \\
\text { oturumu g. gün s. periyoda atanırsa } \\
0, \text { diğer durumlarda }
\end{array}\right.
$$$$
z_{\mathrm{dpg}}:-\left\{\begin{array}{l}
1, \mathrm{~d} \text { dersinin } \mathrm{p} \text {. oturumu g gününe atanırsa } \\
0, \text { diğer durumlarda }
\end{array}\right.
$$

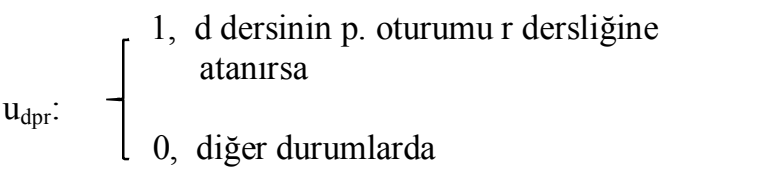

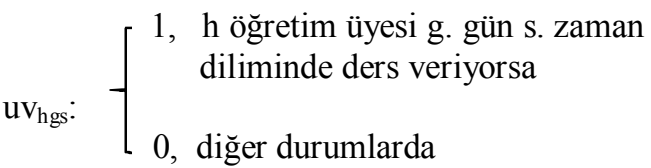

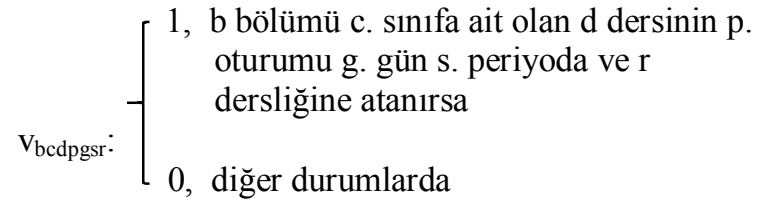$$
\mathrm{w}_{\text {bcdpgsh }}: \begin{cases}1, & \mathrm{~b} \text { bölümü c. sınıfa ait olan d dersinin } \mathrm{p} . \\ & \text { oturumu } \mathrm{h} \text { ögretim üyesinin g. gün } \mathrm{s} . \\ \text { periyoduna atanırsa } & \\ 0, & \text { diğer durumlarda }\end{cases}
$$

$t_{\text {bcgs: }}$ b bölümü $c$. sinıfa ait bloğun $g$ günü $s$. periyoduna atanmıș ders sayısı

$\mathrm{ck}_{\mathrm{d}}$ : $\quad$ c. sinifta verilen $\mathrm{d}$ dersinin (c-1). veya $(\mathrm{c}+1)$. sinuftaki her hangi bir ders veya derslerle çakışan ders saati sayısı

$$
\begin{aligned}
\text { dmy bcdpgs: } & \begin{array}{l}
\text { Doğrusal } \\
\text { doğrusallaştırmak iç̧in kullanılan }
\end{array} \\
& \text { değişkeni }
\end{aligned}
$$

\section{Kisitlar}

Probleme ait kısıtların her biri aşağıda maddeler halinde önce sözel olarak, sonra da matematiksel olarak ifade edilmiştir:

1. Her bölümün her sınıf bloğunda aynı gün ve aynı dilime; zorunlu dersler için en fazla bir ders, seçmeli ve çok gruplu dersler için en fazla iki ders atanabilir. $\mathrm{Bu}$ durum zorunlu derslerin katsayısına 1, çok gruplu ve seçmeli derslerin katsayısına 2 vermek suretiyle sağlanır.

$$
\begin{aligned}
& \sum_{d \in y_{b c}} \sum_{p \leq d p_{d}} x_{b c d p g s} * \mathrm{dk}_{d} \leq 2 \\
& \forall b, c, g, s
\end{aligned}
$$

2. Yukarıdaki kısıtla, çok gruplu derslerin aynı gün aynı dilime atanmasına izin verilir (en fazla iki ders). Ancak dersi tekrar alan öğrencilere alternatif oluşturmak adına aynı derse ait grupların farklı zaman dilimlerine atanması kısıt 2 ile sağlanır.

$$
\begin{aligned}
& \sum_{d \in y_{b c} ;}^{\sum} \sum_{p \leq d p_{d}} x_{b c d p g s} \leq 1 \\
& d t_{d}=2 ; \\
& d g_{d}=\operatorname{ord}(\mathrm{gn}) \\
& \forall b, c, g, s, g n
\end{aligned}
$$

3. Aynı bölümün aynı sınıf bloğunun herhangi bir gününün herhangi bir saatinde, bir seçmeli dersin bir zorunlu tek gruplu dersle çakışması Kısıt 1 ile engellenmiştir. Ancak tüm öğrencilerin bölüm tarafindan sunulan herhangi bir seçmeli dersi alabilmesi için seçmeli derslerin gruplu derslerle de çakışması engellenmelidir.

Örneğin, Endüstri Mühendisliği Bölümü üçüncü sinıfta verilen Üretim Planlama A gruplu ders ile yine aynı bölüm aynı sınıfta verilen Bakım Planlaması dersinin aynı gün aynı periyoda atanması durumunda, Üretim Planlama A dersini almak zorunda olan bir öğrenci Bakım Planlaması dersini seçemeyecektir. Kısıt 3 ile bu durum ortadan kaldırılmıştır.

$$
\begin{aligned}
& x_{b c d^{\prime} 1^{\prime} g_{s}} * 2+\sum_{d d \in y_{b c} ;} x_{b c d d \text { 'l' }^{\prime} g s} \leq 2 \\
& d t_{d d}=2 \\
& \forall b, c ; \forall d \in y_{b c}, d t_{d}=3 ; \forall g, s
\end{aligned}
$$

4. Her dersin her oturumu, zaman çizelgesinde, ilgili bölümün ilgili sınıfina ait bloğa ders süresi kadar atanmalıdır. 


$$
\begin{aligned}
& \sum_{g} \sum_{S} x_{b c d p g s}=d p s d p \\
& \forall b, c ; \forall d \in y_{b c} ; \forall p \leq d p_{d}
\end{aligned}
$$

5. Her dersin her oturumu önceden belirlenen ders saati kadar aralıksız bir şekilde zaman çizelgesine atanmalıdır.

$$
\begin{aligned}
& d p s_{d p} *\left(\mathrm{x}_{b c d p g s}-\mathrm{x}_{b c d p g s+1}\right)+ \\
& \sum_{s s \geq o r d(\mathrm{~s}+2)} x_{b c d p g s s} \leq d p s_{d p} * z d p g \\
& \forall b, c ; \forall d \in y_{b c} ; \forall p \leq d p_{d} ; \\
& \forall g ; \forall s<\operatorname{card}(\mathrm{s})-1
\end{aligned}
$$

6. Her dersin her oturumu sadece bir güne atanabilir.

$$
\begin{aligned}
& \sum_{g} z_{d p g}=1 \\
& \forall b, c ; \forall d \in y_{b c} ; \forall p \leq d p_{d}
\end{aligned}
$$

7. Bir dersin oturumları aynı güne atanamaz.

$$
\begin{aligned}
& \sum_{p \leq d p_{d}}{ }^{z} d p g \leq 1 \\
& \forall d, g
\end{aligned}
$$

8. Bu kısıt sonucu elde edilen $t_{\text {bcgs }}$ değişkeni, ilgili periyotta hangi dersin olduğuna bakılmaksızın zaman çizelgesinde ilgili periyodun dolu olduğunu göstermek için oluşturulmuş ve YYÇ’yi tespit etmek için kullanılmıştır. Bir periyota çok gruplu ders veya seçmeli ders olmak şartıyla en fazla iki ders üst üste çakışabileceğinden, $t_{b c g s}$ değişkeninin en fazla iki değerini alabileceği unutulmamalıdır.

$$
\begin{aligned}
& \sum_{d \in y_{b c}} ; p \leq d p_{d} x_{b c d p g s}=t_{b c g s} \\
& d t_{d} \neq 2 \\
& \forall b, \mathrm{c}, g, s
\end{aligned}
$$

9. Aşağıdaki kısıtla, c. sınıftaki bir dersin bir önceki (c-1). sınıfa ve bir sonraki (c+1). sinıfa ait bir ders ile yan yana çakışan ders süresi hesaplanır.

$c k_{d}=\sum_{p \leq d p_{d}} \sum_{g} \sum_{S} x_{b c d p g s}$

$*\left(\mathrm{t}_{b(\mathrm{c}-1) \mathrm{gs}}+\mathrm{t}_{b(\mathrm{c}+1) \mathrm{gs}}\right)$

$\forall b ; \forall c \in\{1<c<4\} ; \forall d \in y_{b c}$

(9) $\forall h, g, s$
10. YYÇ süresi her ders için bir ders saatini geçemez.

$c_{d} \leq 1 \quad \forall d$

11. Her dersin her oturumu bir dersliğe atanmalı

$\sum_{r \in d r S_{d}} u_{d p r}=1$

$\forall d ; \forall p \leq d p_{d}$

12. Geçiş kısıtı: Bölüm programı ile derslik programı eşleştiriliyor.

$u_{d p r} * x_{b c d p g s}=v_{b c d p g s r}$

$\forall b, c ; \forall d \in y_{b c} ; \forall p \leq d p_{d} ; \forall g, s ; \forall r \in d r s_{d}$

13. Aynı zaman diliminde bir dersliğe en fazla bir ders atanabilir.

$$
\begin{aligned}
& \sum_{b} \sum_{c} \sum_{d \in y_{b c}} ; p \leq d p_{d} v_{b c d p g s r} \leq 1 \\
& \quad d \in d r_{r} \\
& \forall r, g, s
\end{aligned}
$$

14. Geçiş kısıtı: Bölüm programı ile öğretim üyesi programı eşleştiriliyor.

$$
\begin{aligned}
& x_{b c d p g s}=w_{b c d p g s h} \\
& \forall b, c ; \forall d \in y_{b c} ; \forall p \leq d p_{d} ; \forall g, s ; \forall h \in d r h_{d}
\end{aligned}
$$

15. Bir öğretim üyesi aynı anda en fazla bir derse girebilir.

$$
\begin{aligned}
& \sum_{b} \sum_{c} \sum_{d \in y_{b c}} ; p \leq d p_{d} w_{b c d p g s h} \leq 1 \\
& \quad d \in d h_{h} \\
& \forall h, g, s
\end{aligned}
$$

16. Bir öğretim üyesinin, hangi dersi verdiğine bakılmaksızın g. gün ve s. zaman diliminde ders verip vermeği hesaplanıyor. $\mathrm{Bu}$ değişken amaç fonksiyonunda kullanılacaktır.

$$
\begin{gathered}
\sum_{b} \sum_{c} \sum_{d \in y_{b c}} ; p \leq d p_{d} w_{b c d p g s h}=u v_{h g s} \\
d \in d h_{h}
\end{gathered}
$$




\section{Amaç Fonksiyonu}

Enbüyüklenmeye çalışılan ve öğretim üyelerinin unvanlarını ile tercihlerini dikkate alan toplam memnuniyet değeri aşağıdaki gibi hesaplanmaktadır:

$$
\begin{aligned}
& \text { TopMemnuniyet }= \\
& \sum_{h} \sum_{g} \sum_{S} u v_{h g s}{ }^{*}{ }^{t r c}{ }_{h g s} * u n v_{h}
\end{aligned}
$$

\section{DOĞRUSAL OLMAYAN KISITLARIN DOĞRUSALLAŞTIRILMASI (LINEARIZATION OF THE NON-LINEAR CONSTRAINTS)}

Bu bölümde iki değişkenin çarpımını içeren 9 ve 12 numaralı doğrusal olmayan kisıtların doğrusallaştırılmasından bahsedilmiştir.

\section{a) 9 numaralı kısıtın doğrusallaștırılması:}

Bu kısıtta, her ders için YYÇ süreleri, bir tam sayılı bir de (0-1) değişkenin çarpımıyla hesaplamaktadır. Öncelikle anlam karmaşasının önüne geçmek için 9 numaralı kısıtta parantez içinde verilen toplam, 9a kısıtında $t t$ isimli bir değişkene aktarılmıştır. Bir zaman dilimine çok gruplu veya seçmeli ders olmak şartıyla en fazla iki ders üst üste atanabileceği, problemle ilgili genel kavramlar kısminda ifade edilmiştir. Dolayısıyla ilgili dersin ait olduğu sınıfın (c) bir alt (c-1) ve/veya bir üst (c+1) sınıfının s. zaman diliminde en fazla dört ders ile çakışabileceğinden $t t$ değeri 0 ile 4 arasında tutulmuştur. Şekil 2'de görüldüğü gibi 33 numaralı dersin 2. oturumu, Pazartesi günü 2. zaman diliminde; $27,32,47$ ve 50 nolu derslerin ilk oturumları ile yan yana çakışmıştır.

$$
\begin{aligned}
& t_{b(c-1) \mathrm{gs}}=t_{b(\mathrm{c}-1) \mathrm{gs}}+t_{b(\mathrm{c}+1) \mathrm{gs}} \\
& \forall b, g, s ; \forall c \in\{1<c<4\}
\end{aligned}
$$

\begin{tabular}{|c|c|c|c|c|c|}
\hline GÜN & PRYT. & I. SINIF & II.SINIF & III.Sinıf & IV. Sinif \\
\hline \multirow{5}{*}{ 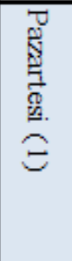 } & 1 & $(27,1)$ & & $(43,2)$ & \\
\hline & 2 & $(27,1)(32,1)$ & $(33,2)$ & $(47,1)(50,1)$ & \\
\hline & 3 & $(27,1)(32,1)$ & & $(47,1)$ & \\
\hline & 4 & $(32,1)$ & & $(47,1)$ & \\
\hline & 5 & & & & \\
\hline
\end{tabular}

Şekil 2. Maksimum yan yana çakışmaya ait bir örmek (A sample for maksimum side by side collision)

Bu eşitlikle 9 numaralı kısıt aşağıdaki şekle gelmiştir:

$$
\begin{aligned}
& c k_{d}=\sum_{p \leq d p_{d}} \sum_{g} \sum_{s} x_{b c d p g s} * \mathrm{tt}_{b(\mathrm{c}-1) \mathrm{gs}} \\
& \forall b ; \forall c \in\{1<c<4\} ; \forall d \in y_{b c}
\end{aligned}
$$

$d m y$ isimli pozitif tam sayılı değişken, $x$ ve $t t$ değişkenlerinin çarpımını ifade etmektedir ve $9 \mathrm{~b}$ kısıtı aşağıdaki üç kısıtla doğrusallaştırılmıştır.

$$
\begin{aligned}
& d m y_{b c d p g s} \leq 4^{*} x_{b c d p g s} \\
& \forall b ; \forall c \in\{1<c<4\} ; \\
& \forall d \in y_{b c} ; \forall p \leq d p_{d} ; g, s \\
& d m y_{b c d p g s} \leq t t_{b(c-1) g s} \\
& \forall b ; \forall c \in\{1<c<4\} ; \\
& \forall d \in y_{b c} ; \forall p \leq d p_{d} ; g, s \\
& d m y_{b c d p g s} \geq t t_{b(c-1) g s}-4 *\left(1-x_{b c d p g s}\right) \\
& \forall b ; \forall c \in\{1<c<4\} ; \\
& \forall d \in y_{b c} ; \forall p \leq d p d ;, s
\end{aligned}
$$

$x$ değişkeninin alacağ 0 ve 1 değerlerine ve $t t$ değişkeninin 0-4 aralığında alacağı tamsayı değerlere karşılık $d m y$ değişkeninin alacağı değerler Tablo 1'de verilmiştir. Karşılaşılabilir bütün durumlar ve sonuçlarıyla bu yöntemin geçerliliği Tablo 1'de gösterilmiştir.

$$
\begin{aligned}
& c_{d}=\sum_{p \leq d p_{d}} \sum_{g} \sum_{s} d m y_{b c d p g s} \\
& \forall b ; \forall c \in\{1<c<4\} ; \forall d \in y_{b c}
\end{aligned}
$$

Kısıt 9f ile yukarıdaki üç kısıtla elde edilen $d m y$ değerleri; bir dersin bütün oturumları, zaman çizelgesindeki bütün gün ve periyotlar için toplanarak her ders için yan yana çakışma sayısını ifade eden $c k_{d}$ değeri bulunmaktadır.

\section{b) 12 numaralı kısıtın doğrusallaștırılması:}

Bir diğer doğrusal olmayan kısıt, bölüm programı ile derslik programının eşleştirildiği ve iki (0-1) değişkenin çarpımını içeren 12 numaralı kısıttır. Aşağıdaki üç kısıt seti ile doğrusal olmayan 12 numaralı kısıt doğrusallaştırılmıştır.

$$
\begin{aligned}
& v_{b c d p g s r} \leq u_{d p r} \\
& \forall b, c ; \forall d \in y_{b c} ; \forall p \leq d p_{d} ; \\
& \forall g, s ; \forall r \in d r s_{d}
\end{aligned}
$$

$$
\begin{aligned}
& v_{b c d p g s r} \leq x_{b c d p g s} \\
& \forall b, c ; \forall d \in y_{b c} ; \forall p \leq d p_{d} ; \\
& \forall g, s ; \forall r \in d r s_{d}
\end{aligned}
$$


Tablo 1. $x$ ve $t t$ değişkenlerinin alacağı değerlere karşılık $d m y$ değişkeninin alacağı değerler (Values of variable dmy versus values of variables $\mathrm{x}$ and $\mathrm{tt}$ )

\begin{tabular}{|c|c|c|c|c|c|c|c|}
\hline $\mathbf{x}$ & tt & $\begin{array}{c}\text { Kisıtlar } \\
(9 \mathrm{c}, 9 \mathrm{~d}, 9 \mathrm{e})\end{array}$ & $x^{*} t t=d m y$ & $\mathbf{x}$ & tt & $\begin{array}{c}\text { Kisitlar } \\
(9 \mathrm{c}, 9 \mathrm{~d}, 9 \mathrm{e})\end{array}$ & $x^{*} t \mathrm{t}=\mathrm{dmy}$ \\
\hline 1 & 0 & $\begin{array}{c}\mathrm{dmy} \leq 4 * 1 \\
\mathrm{dmy} \leq 0 \\
\mathrm{dmy} \geq 0-4 *(1-1)\end{array}$ & 0 & 0 & 0 & $\begin{array}{c}\mathrm{dmy} \leq 4 * 0 \\
\mathrm{dmy} \leq 0 \\
\mathrm{dmy} \geq 0-4 *(1-0)\end{array}$ & 0 \\
\hline 1 & 1 & $\begin{array}{c}\mathrm{dmy} \leq 4 * 1 \\
\mathrm{dmy} \leq 1 \\
\mathrm{dmy} \geq 1-4 *(1-1) \\
\end{array}$ & 1 & 0 & 1 & $\begin{array}{c}\mathrm{dmy} \leq 4 * 0 \\
\mathrm{dmy} \leq 1 \\
\mathrm{dmy} \geq 1-4 *(1-0)\end{array}$ & 0 \\
\hline 1 & 2 & $\begin{array}{c}\mathrm{dmy} \leq 4 * 1 \\
\mathrm{dmy} \leq 2 \\
\mathrm{dmy} \geq 2-4 *(1-1)\end{array}$ & 2 & 0 & 2 & $\begin{array}{c}\mathrm{dmy} \leq 4 * 0 \\
\mathrm{dmy} \leq 2 \\
\mathrm{dmy} \geq 2-4 *(1-0)\end{array}$ & 0 \\
\hline 1 & 3 & $\begin{array}{c}\mathrm{dmy} \leq 4 * 1 \\
\mathrm{dmy} \leq 3 \\
\mathrm{dmy} \geq 3-4 *(1-1)\end{array}$ & 3 & 0 & 3 & $\begin{array}{c}\mathrm{dmy} \leq 4 * 0 \\
\mathrm{dmy} \leq 3 \\
\mathrm{dmy} \geq 3-4 *(1-0)\end{array}$ & 0 \\
\hline 1 & 4 & $\begin{array}{c}\mathrm{dmy} \leq 4 * 1 \\
\mathrm{dmy} \leq 4 \\
\mathrm{dmy} \geq 4-4 *(1-1)\end{array}$ & 4 & 0 & 4 & $\begin{array}{c}\mathrm{dmy} \leq 4 * 0 \\
\mathrm{dmy} \leq 4 \\
\mathrm{dmy} \geq 4-4 *(1-0)\end{array}$ & 0 \\
\hline
\end{tabular}

$$
\begin{aligned}
& v_{b c d p g s r} \geq x_{b c d p g s}+u_{d p r}-1 \\
& \forall b, c ; \forall d \in y_{b c} ; \forall p \leq d p_{d} ; \\
& \forall g, s ; \forall r \in d r s_{d}
\end{aligned}
$$

Karşılaşılabilir bütün durumlar sonuçlarıyla Tablo 2'de gösterilmiştir.

Tablo 2. $u$ ve $x$ değişkenlerinin alabileceği $0-1$

\begin{tabular}{|c|c|c|c|c|c|c|c|}
\hline $\mathbf{u}$ & $\mathbf{x}$ & $\begin{array}{c}\text { Kisıtlar } \\
(12 \mathrm{a}, 12 \mathrm{~b}, \\
12 \mathrm{c})\end{array}$ & $\mathbf{v}$ & $\mathbf{u}$ & $\mathbf{X}$ & $\begin{array}{c}\text { Kisıtlar } \\
(12 \mathrm{a}, 12 \mathrm{~b}, \\
12 \mathrm{c})\end{array}$ & $\mathbf{v}$ \\
\hline 0 & 0 & $\begin{array}{c}\mathrm{v} \leq 0 \\
\mathrm{v} \leq 0 \\
\mathrm{v} \geq 0+0-1\end{array}$ & 0 & 1 & 0 & $\begin{array}{c}\mathrm{v} \leq 1 \\
\mathrm{v} \leq 0 \\
\mathrm{v} \geq 1+0-1\end{array}$ & 0 \\
\hline 0 & 1 & $\begin{array}{c}\mathrm{v} \leq 0 \\
\mathrm{v} \leq 1 \\
\mathrm{v} \geq 0+1-1\end{array}$ & 0 & 1 & 1 & $\begin{array}{c}\mathrm{v} \leq 1 \\
\mathrm{v} \leq 1 \\
\mathrm{v} \geq 1+1-1\end{array}$ & 1 \\
\hline
\end{tabular}
değerlerine karşılık $v$ değişkeninin alacağı değerler (Values of variable $v$ versus $0-1$ values of variables $u$ and $x$ )

Görüldüğü gibi kısıtların doğrusallaştırılmasından sonra model tam sayılı doğrusal hale gelmiştir. $\mathrm{Bu}$ dönüşüm, modele fazladan 34.515 kısit ve 2.025 değişken eklenmesini neden olsa da, ilk haliyle 48 saatte uygun çözüme ulaşılamazken doğrusallaştırma sonrasında 9417 saniyede optimum çözüme ulaşmıştır.

\section{6. ÖNERILEN TAM SAYILI DOĞRUSAL PROGRAMLAMA MODELININ KÜÇÜK BİR ÖRNEK ÜZERINDE DENENMESİ (TESTING PROPOSED INTEGER LINEAR PROGRAMMING MODEL WITH A SMALL SIZE TEST PROBLEM)}

$\mathrm{Bu}$ bölümde öncelikle modelin boyutu her k1sıt seti için değişken ve kısıt sayısı açısından parametrik olarak hesaplanmış ve Tablo 3'te sunulmuştur. Modele ait parametreler Bölüm 3.1'de sunulmuştur.
Ancak parametrik gösterim için ilave parametrelere ihtiyaç duyulmuştur. $\mathrm{Bu}$ parametreler aşağıda belirtilmiştir.

SGrup $_{\mathrm{bc}}$ : b bölümü c sınıfina ait gruplu ders sayısı $\mathrm{SSec}_{\mathrm{bc}}$ : $\quad$ b bölümü c sınıfina ait seçmeli ders sayısı SZorn $_{\mathrm{bc}}$ : $\quad$ b bölümü c sınıfina ait zorunlu ders sayısı SDerslik $_{\mathrm{p}}$ : $\mathrm{p}$ oturumunun yapılabileceği dersliklerin sayıs1

SOturum $_{\mathrm{r}}$ : $\mathrm{r}$ dersliğinde yapılabilecek oturumların sayisı

SOturum $_{h}: h$ öğretim üyesi tarafindan verilen oturumların sayısı

P: $\quad$ Problemdeki toplam oturum sayıs1

P(2-3): Her bölümün 2 ve 3 . sinıflarındaki oturum sayıs1

D(2-3): $\quad$ Her bölümün 2 ve 3 . sinıflarındaki ders sayıs1

GS: $\quad$ Gruplu ders sayısı $\left(G S=\sum_{b} \sum_{c} S G r u p_{b, c}\right)$

Model öncelikle tüm fakülte (8 bölüm) için kurulmuştur. 551.865 kisıt ve 1.651 .999 değişkenden oluşan model, CPLEX karma tam sayılı programlama çözücüsü ile CoreTM 2 Quard CPU, $2.66 \mathrm{GHz}$ işlemci ve 4 GB RAM özelliklerine sahip bilgisayarda 10 saat çalıştırılmış ancak uygun çözüme dahi ulaşılamamıştır. Bu yüzden modeli test etmek için daha küçük boyutlu bir örnek kullanılmıştır. Bu örnekte iki bölüm bulunmaktadır. Her iki bölüm de dört yıllık eğitim vermekte olup, dersler en fazla iki oturumda yapılmaktadır. Derslerin ait oldukları bölüm, sınıf ve oturum bazlı ders süreleri Tablo 4'te verilmiştir. Dersler, bölüm programlarında ders numarası ve oturum numarası ile $(*, *)$ kalıbında ifade edilmiştir. Fakülte müfredatında dersler; zorunlu (1), çok gruplu (2) ve seçmeli (3) olmak üzere üçe ayrılmıştır. Derslerin hangi gruba ait olduğu ve model için gerekli diğer bilgiler Tablo 4'te sunulmuştur. Modelin testi için verilen bu örnekte 8 derslik (D1, 
Tablo 3. Önerilen modelin boyutunun parametrik olarak gösterimi (Parametric presentation of proposed model's size)

\begin{tabular}{|c|c|c|}
\hline $\begin{array}{l}\text { Kisit } \\
\text { Seti }\end{array}$ & Kisıt Sayısı & Değişken Sayısı \\
\hline 1 & $\mathrm{G} * \mathrm{~S} * \mathrm{~B} * 4$ & $\mathrm{G} * \mathrm{~S} * \mathrm{P}$ \\
\hline 2 & $\mathrm{G} * \mathrm{~S} * \mathrm{GN}$ & $\mathrm{G} * \mathrm{~S} * \mathrm{GS}$ \\
\hline 3 & $\begin{array}{l}\operatorname{SGrup}_{b, c}>0 \Rightarrow k_{b, c}=S \operatorname{Sec}_{b, c} * G^{*} S \\
\operatorname{SGrup}_{b, c}=0 \Rightarrow k_{b, c}=0 \\
\sum_{b} \sum_{c} k_{b, c}\end{array}$ & $\begin{array}{l}\operatorname{SGrup}_{b, c}>0 \wedge S \operatorname{Sec}_{b, c}>0 \Rightarrow d_{b, c}=\operatorname{SSec}_{b, c} * G^{*} S\left(\operatorname{SGrup}_{b, c}+1\right) \\
\operatorname{SGrup}_{b, c}=0 \vee S \operatorname{Sec}_{b, c}=0 \Rightarrow d_{b, c}=0 \\
\sum_{b} \sum_{c} d_{b, c}\end{array}$ \\
\hline 4 & $\mathrm{P}$ & $\mathrm{P} *_{\mathrm{G}} *_{\mathrm{S}}$ \\
\hline 5 & $\mathrm{P} * \mathrm{G} *(\mathrm{~S}-2)$ & $P * G *\left(\frac{(\mathrm{S}+1) *(\mathrm{~S}+2)}{2}-6\right)$ \\
\hline 6 & $\mathrm{P}$ & $\mathrm{P} * \mathrm{G}$ \\
\hline 7 & $D^{*} \mathrm{G}$ & $\mathrm{P} * \mathrm{G}$ \\
\hline 8 & $\mathrm{G} * \mathrm{~S} * \mathrm{~B} * 4$ & $\sum_{b} \sum_{c} G^{*} S *\left(\operatorname{Ssec}_{b, c}+\operatorname{SZorn}_{b, c}+1\right)$ \\
\hline $9 \mathrm{a}$ & $G * S * B * 2$ & $\mathrm{G} * \mathrm{~S} * \mathrm{~B} * 2 * 3$ \\
\hline $9 \mathrm{c}$ & $\mathrm{G} * \mathrm{~S} * \mathrm{P}(2-3)$ & $\mathrm{G} * \mathrm{~S} * \mathrm{P}(2-3) * 2$ \\
\hline $9 \mathrm{~d}$ & $\mathrm{G} * \mathrm{~S} * \mathrm{P}(2-3)$ & $\mathrm{G} * \mathrm{~S} * \mathrm{P}(2-3) * 2$ \\
\hline $9 \mathrm{e}$ & $\mathrm{G} * \mathrm{~S} * \mathrm{P}(2-3)$ & $\mathrm{G} * \mathrm{~S} * \mathrm{P}(2-3) * 3$ \\
\hline $9 \mathrm{f}$ & $\mathrm{D}(2-3)$ & $\sum_{\substack{d=3 \\
d=4}} G^{*} S * d p_{d}$ \\
\hline 10 & D & $\mathrm{D}$ \\
\hline 11 & $\mathrm{P}$ & $\sum_{p} S \operatorname{Derslik}_{p}$ \\
\hline $12 \mathrm{a}$ & $\sum_{p}\left(\operatorname{SDerslik}_{p} * G^{*} S\right)$ & $\sum_{p}\left(\operatorname{SDerslik}_{p} * G * S * 2\right)$ \\
\hline $12 \mathrm{~b}$ & $\sum_{p}\left(\right.$ SDerslik $\left._{p}^{*} G^{*} S\right)$ & $\sum_{p}\left(\operatorname{SDerslik}_{p} * G * S * 2\right)$ \\
\hline $12 \mathrm{c}$ & $\sum_{p}\left(\operatorname{SDerslik}_{p} * G^{*} S\right)$ & $\sum_{p}\left(\operatorname{SDerslik}_{p} * G * S * 3\right)$ \\
\hline 13 & $\mathrm{R} * \mathrm{G} * \mathrm{~S}$ & $\sum_{r}\left(\right.$ SOturum $\left._{r} * G * S\right)$ \\
\hline 14 & $\mathrm{P} * \mathrm{G} * \mathrm{~S}$ & $\mathrm{P} * \mathrm{G} * \mathrm{~S} * 2$ \\
\hline 15 & $\mathrm{H}^{*} \mathrm{G} * \mathrm{~S}$ & $\sum_{h}\left(\right.$ SOturum $\left._{h} * G * S\right)$ \\
\hline 16 & $\mathrm{H} * \mathrm{G} * \mathrm{~S}$ & $\sum_{h}\left(\right.$ SOturum $\left._{h} * G^{*} S+1\right)$ \\
\hline 17 & 1 & $\mathrm{D}+\mathrm{G} * \mathrm{~S} * \mathrm{H}$ \\
\hline
\end{tabular}

$\mathrm{D} 2, \ldots, \mathrm{D} 8)$ ve 7 öğretim üyesi $(\mathrm{H} 1, \mathrm{H} 2, \ldots, \mathrm{H} 7)$ bulunmaktadır. Tablo 4'ten görüleceği üzere derslerin hangi öğretim üyesi tarafindan verileceği önceden bilinmektedir. Model, bölümlerin fakülte bünyesindeki bütün derslikleri kullanabileceği şekilde tasarlanmıştır. Bölüm 1 dersleri için D4, D5, D6, D7 derslikleri, Bölüm 2 dersleri için D1, D2, D3 ve D8 derslikleri tahsis edilmiştir. Grup numarası çok gruplu farklı derslerin aynı gün aynı periyota atanmasını sağlayacak parametredir. Örneğin, 1 grup numaralı dersler aynı dersin A ve B gruplarıdır ve aynı gün ve aynı periyota atanamazlar. Geliştirilen modelde amaç, öğretim üyelerinin verdikleri dersleri olabildiğince en çok istedikleri zaman dilimlerine atamaktır. Yedi öğretim üyesine ait periyot tercihleri Şekil 3'te sunulmuştur. 
Tablo 4. Test problemine ait veriler (Data belong to test problem)

\begin{tabular}{|c|c|c|c|c|c|c|c|c|}
\hline & \multirow{3}{*}{$\begin{array}{c}\text { Ders } \\
\text { No (d) } \\
1 \\
\end{array}$} & \multicolumn{2}{|c|}{$\begin{array}{l}\text { Oturum } \\
\text { (p) }\end{array}$} & \multirow{3}{*}{$\begin{array}{c}\text { Tipi } \\
\left(\mathbf{d t}_{\mathbf{d}}\right)\end{array}$} & \multirow{3}{*}{$\begin{array}{c}\text { Katsayı } \\
\left(\mathbf{d k}_{\mathbf{d}}\right) \\
2 \\
2\end{array}$} & \multirow[t]{2}{*}{$\begin{array}{c}\text { Grup No } \\
\text { (gn) }\end{array}$} & \multirow[t]{2}{*}{$\begin{array}{c}\text { Ö. Üyesi } \\
\text { (h) }\end{array}$} \\
\hline & & & 1 & 2 & & & & \\
\hline \multirow{25}{*}{ 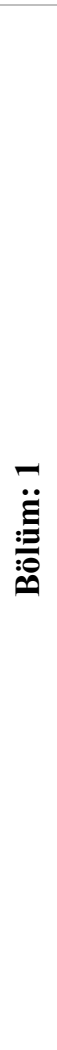 } & \multirow{9}{*}{$\underset{\ddot{\Xi}}{\ddot{\Xi}}$} & & 2 & 0 & & & & H1 \\
\hline & & 2 & 2 & 1 & 1 & 2 & & $\mathrm{H} 2$ \\
\hline & & 3 & 1 & 2 & 1 & 2 & & $\mathrm{H} 3$ \\
\hline & & 4 & 2 & 2 & 1 & 2 & & $\mathrm{H} 4$ \\
\hline & & 5 & 1 & 2 & 1 & 2 & & H5 \\
\hline & & 6 & 3 & 0 & 2 & 1 & 1 & H6 \\
\hline & & 7 & 3 & 0 & 2 & 1 & 1 & $\mathrm{H} 7$ \\
\hline & & 19 & 3 & 0 & 2 & 1 & 2 & $\mathrm{H} 4$ \\
\hline & & 20 & 3 & 0 & 2 & 1 & 2 & H5 \\
\hline & \multirow{6}{*}{$\stackrel{N}{\ddot{\Xi}}$} & 8 & 1 & 2 & 1 & 2 & & H6 \\
\hline & & 9 & 3 & 0 & 1 & 2 & & $\mathrm{H} 7$ \\
\hline & & 10 & 2 & 1 & 1 & 2 & & H5 \\
\hline & & 11 & 2 & 1 & 1 & 2 & & $\mathrm{H} 1$ \\
\hline & & 12 & 2 & 1 & 1 & 2 & & $\mathrm{H} 2$ \\
\hline & & 13 & 2 & 1 & 1 & 2 & & $\mathrm{H} 3$ \\
\hline & \multirow{5}{*}{$\stackrel{m}{\ddot{\Xi}}$} & 14 & 2 & 1 & 1 & 2 & & $\mathrm{H} 4$ \\
\hline & & 15 & 3 & 0 & 3 & 1 & & $\mathrm{H} 7$ \\
\hline & & 16 & 3 & 0 & 3 & 1 & & H6 \\
\hline & & 17 & 2 & 1 & 1 & 2 & & $\mathrm{H} 7$ \\
\hline & & 18 & 2 & 1 & 1 & 2 & & $\mathrm{H} 3$ \\
\hline & \multirow{5}{*}{$\stackrel{+}{\ddot{\ddot{\Xi}}}$} & 21 & 2 & 1 & 1 & 2 & & H1 \\
\hline & & 22 & 2 & 0 & 1 & 2 & & $\mathrm{H} 2$ \\
\hline & & 23 & 3 & 0 & 1 & 2 & & H6 \\
\hline & & 24 & 2 & 1 & 1 & 2 & & $\mathrm{H} 7$ \\
\hline & & 25 & 2 & 1 & 1 & 2 & & H6 \\
\hline \multirow{23}{*}{ 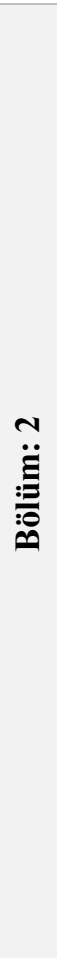 } & \multirow{7}{*}{$\underset{\ddot{\Xi}}{\ddot{\Xi}}$} & 26 & 2 & 1 & 1 & 2 & & $\mathrm{H} 1$ \\
\hline & & 27 & 3 & 0 & 2 & 1 & 3 & $\mathrm{H} 7$ \\
\hline & & 28 & 3 & 0 & 2 & 1 & 3 & $\mathrm{H} 2$ \\
\hline & & 29 & 2 & 1 & 1 & 2 & & H3 \\
\hline & & 30 & 2 & 1 & 1 & 2 & & H4 \\
\hline & & 31 & 3 & 0 & 2 & 1 & 4 & H5 \\
\hline & & 32 & 3 & 0 & 2 & 1 & 4 & H6 \\
\hline & \multirow{7}{*}{$\stackrel{N}{\ddot{\Xi}}$} & 33 & 2 & 1 & 1 & 2 & & $\mathrm{H} 7$ \\
\hline & & 34 & 1 & 2 & 1 & 2 & & H6 \\
\hline & & 35 & 2 & 1 & 1 & 2 & & $\mathrm{H} 7$ \\
\hline & & 36 & 1 & 2 & 1 & 2 & & H4 \\
\hline & & 37 & 2 & 1 & 1 & 2 & & H1 \\
\hline & & 38 & 2 & 1 & 1 & 2 & & $\mathrm{H} 2$ \\
\hline & & 39 & 1 & 2 & 1 & 2 & & $\mathrm{H} 3$ \\
\hline & \multirow{4}{*}{$\stackrel{m}{\ddot{\Xi}}$} & 40 & 2 & 1 & 1 & 2 & & H4 \\
\hline & & 41 & 2 & 1 & 1 & 2 & & H6 \\
\hline & & 42 & 2 & 1 & 1 & 2 & & H1 \\
\hline & & 43 & 2 & 1 & 1 & 2 & & $\mathrm{H} 2$ \\
\hline & \multirow{5}{*}{$\stackrel{\nabla}{\ddot{\Xi}}$} & 44 & 2 & 1 & 1 & 2 & & H6 \\
\hline & & 45 & 2 & 1 & 1 & 2 & & H7 \\
\hline & & 46 & 2 & 1 & 1 & 2 & & H6 \\
\hline & & 47 & 3 & 0 & 3 & 1 & & $\mathrm{H} 2$ \\
\hline & & 48 & 3 & 0 & 3 & 1 & & H3 \\
\hline
\end{tabular}



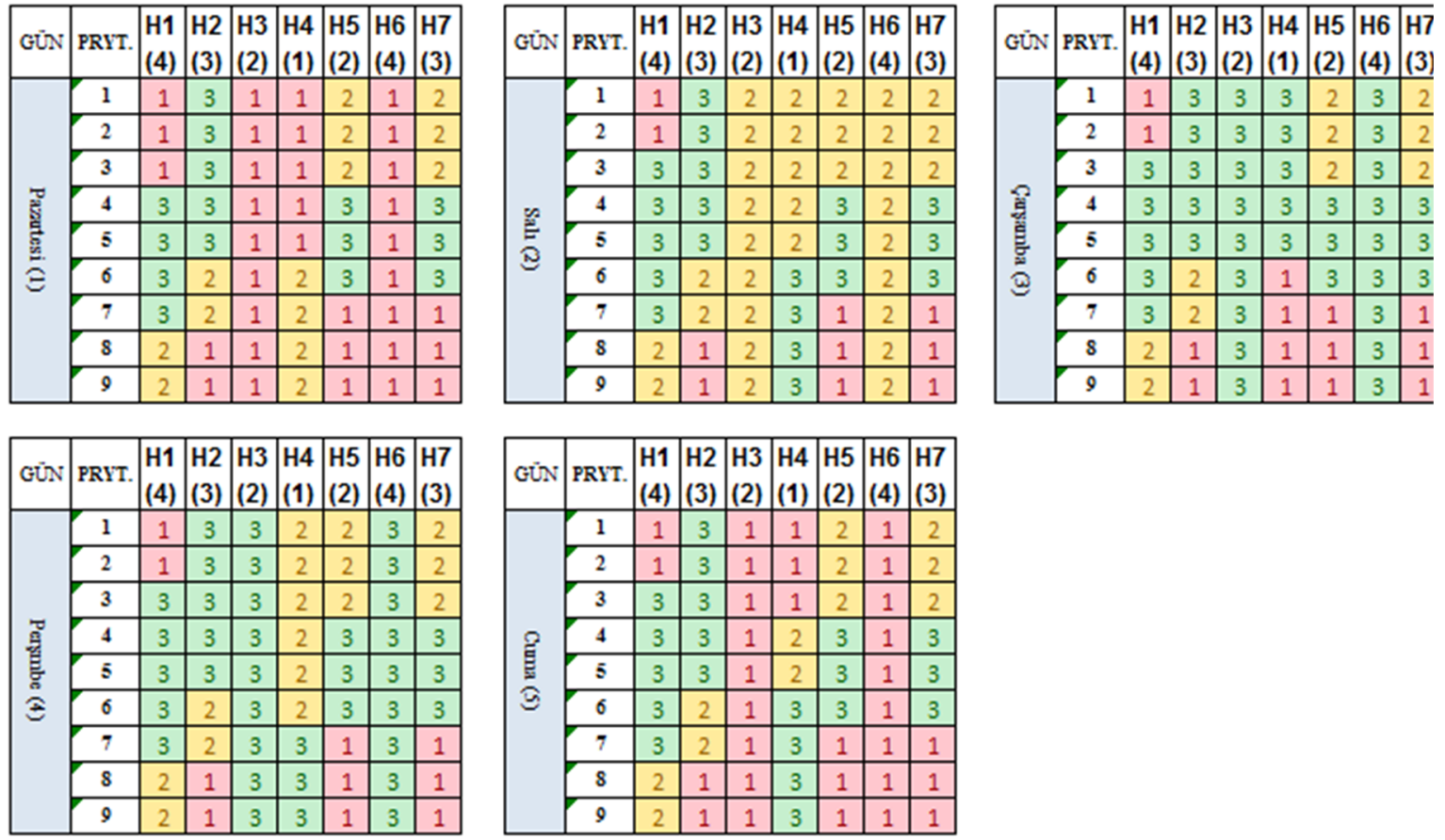

Şekil 3. Yedi öğretim üyesinin zaman dilimi tercihleri (Time slot preferences of seven lecturers)

1 mümkünse istemiyorum, 2 olabilir ve 3 uygun anlamına gelmektedir. Ayrıca öğretim üyelerinin unvanlarına göre katsayıları parantez içinde belirtilmiştir. Örneğin 3. sütundaki öğretim üyesi (H1) profesör unvanındadır ve katsayısı (4) olarak belirlenmiştir. $\mathrm{Bu}$ şekilde öğretim üyelerinin unvanlarını da dikkate alarak, derslerinin mümkün olduğunca tercih ettikleri periyotlara atanması sağlanmaktadır.

Problem, GAMS matematiksel programlama dili ile formüle edilmiş ve CPLEX karma tam sayılı programlama çözücüsü ile Core ${ }^{\mathrm{TM}} 2$ Quard CPU, 2.66 $\mathrm{GHz}$ işlemci ve $4 \mathrm{~GB}$ RAM özelliklerine sahip bilgisayarda çözülmüştür. 12.660'1 (0-1) değişken olmak üzere toplam 15.095 değişkeni ve 29.272 kısıtı olan problemin optimum çözümüne 9417 saniyede ulaşılmıştır.

\section{SONUÇLAR VE TARTIŞMALAR (RESULTS AND DISCUSSION)}

Modelin denenmesi için oluşturulan test problemi çözülmüş ve elde edilen sonuç Şekil 4'teki gibi görselleştirilmiştir. Şekil 4'te, her iki bölüme ait programlar, derslik ve öğretim üyesi programları 3 ayrı blok halinde sunulmuştur. Her oturum farklı bir renk ile ifade edilmiştir. Örneğin bölüm programına baktığımızda, 1. Bölüm 4. Sinıfa ait olan $(21,1)$ oturumunun (turkuaz renkli) pazartesi 1 ve 2 . periyotlara atandığı görülmektedir. Aynı şekilde derslik programına bakıldığında bu oturumun D6 dersliğine atandığ bakıldığında H1 öğretim üyesine ait bir ders olduğu görülmektedir (birbirleri ile ilişkili periyotlar aynı renk ile boyanmıştır). Öğretim üyelerinin sunulduğu blokta parantez içindeki "( )" değerler ilgili öğretim üyesine ait unvan katsayısını belirtmektedir. Yine aynı bloktaki hücre içi değerler Şekil 3'te belirtilen öğretim üyelerinin tercih katsayılarını ifade etmektedir. Bu bölümde, elde edilen sonuçlar Şekil 4 yardımıyla problemin kısıtlarına göre aşağıdaki gibi değerlendirilmiştir:

Tablo 4'te verilen 48 dersin tamamı ait olduğu bölüm ve sınıf bloğuna gelecek şekilde zaman çizelgesine (bölüm programına) atanmıştır. Zorunlu dersler üst üste çakıştırılmamıştır. Çok gruplu dersler üst üste çakışacağı zaman, farklı derslere ait grupların üst üste çakışması kısıtı sağlanmıştır. Örneğin çok gruplu derslerden 6 ve 20 numaralı dersler 3. gün (Çarşamba günü) 7,8 ve 9 . periyotlarda üst üste çakışmıştır. Çakışan bu derslerden birinin 1 numaralı gruba diğerinin 2 numaralı gruba ait olduğuna dikkat edilmelidir. Geliştirilen modelde seçmeli derslere üst üste çakışma imkânı verilmiş, ancak verilen sonuç tablosunda böyle bir durum ortaya çıkmamıștır. Şekil 4'ün derslikler ve öğretim üyeleri bölümünde hücreler, ilgili periyota atanmış dersin rengi ile boyanmıștır. Böylece aynı anda bir derslikte birden fazla ders işlenememesi ve bir öğretim üyesinin aynı periyotta birden fazla ders verememesi kısıtlarının sağlandığı açıkça görülmektedir. Çok gruplu dersler hariç, zaman çizelgesi yan yana çakışma olmaksızın oluşturulmuştur. Çözüm sonunda öğretim üyelerinin tercihlerine göre atanma durumları Tablo 5'te görüldüğü gibi oluşmuştur. Sonuç olarak toplam memnuniyet seviyesi 766 olarak bulunmuştur. Ayrıca Tablo 5'te her öğretim üyesinin, tercih tipine göre zaman dilimlerine atanan ders saati sayısı ve unvanına 

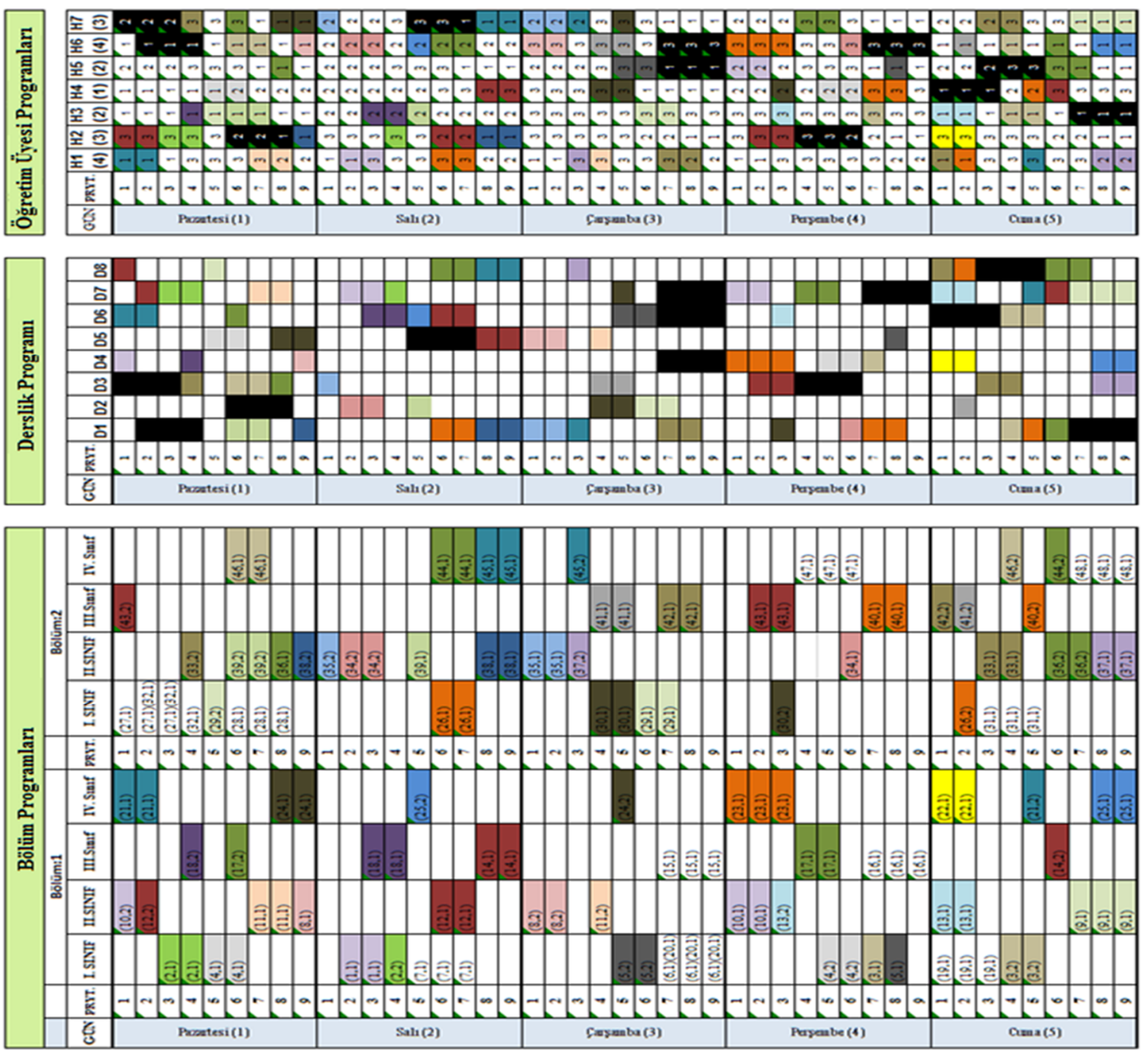

Şekil 4. Test probleminin çözümümü sonucu oluşan zaman çizelgesi (Generated timetable according to solution of test problem)

Tablo 5. Sonucun öğretim üyelerinin tercihlerine göre incelenmesi (Examination of results according to preference of lecturers)

\begin{tabular}{|c|c|c|c|c|c|c|c|c|c|c|c|c|c|c|c|}
\hline & \multicolumn{2}{|c|}{ H1 (4) } & \multicolumn{2}{|c|}{ H2 (3) } & \multicolumn{2}{|c|}{ H3 (2) } & \multicolumn{2}{|c|}{ H4 (1) } & \multicolumn{2}{|c|}{ H5 (2) } & \multicolumn{2}{|c|}{ H6 (4) } & \multicolumn{2}{|c|}{ H7 (3) } & \multirow{6}{*}{$\stackrel{3}{\stackrel{3}{3}}$} \\
\hline $\begin{array}{l}\text { Tercih } \\
\text { Tipi }\end{array}$ & $\begin{array}{l}\text { Ders } \\
\text { Saati }\end{array}$ & Puan & $\begin{array}{l}\text { Ders } \\
\text { Saati }\end{array}$ & Puan & $\begin{array}{l}\text { Ders } \\
\text { Saati }\end{array}$ & Puan & $\begin{array}{l}\text { Ders } \\
\text { Saati }\end{array}$ & Puan & $\begin{array}{l}\text { Ders } \\
\text { Saati }\end{array}$ & Puan & $\begin{array}{l}\text { Ders } \\
\text { Saati }\end{array}$ & Puan & $\begin{array}{l}\text { Ders } \\
\text { Saati }\end{array}$ & Puan & \\
\hline 1 & 5 & 5 & 3 & 3 & 11 & 11 & 4 & 4 & 6 & 6 & 11 & 11 & 8 & 8 & \\
\hline 2 & 4 & 8 & 5 & 10 & 3 & 6 & 5 & 10 & 3 & 6 & 5 & 10 & 8 & 16 & \\
\hline 3 & 8 & 24 & 11 & 33 & 4 & 12 & 7 & 21 & 5 & 10 & 14 & 28 & 8 & 24 & \\
\hline Toplam & 17 & 37 & 19 & 47 & 18 & 29 & 16 & 35 & 14 & 22 & 30 & 49 & 24 & 48 & \\
\hline $\begin{array}{l}\text { Ağırlıklı } \\
\text { Toplam }\end{array}$ & & 148 & & 141 & & 58 & & 35 & & 44 & & 196 & & 144 & 766 \\
\hline
\end{tabular}

göre memnuniyeti görülmektedir. Örneğin, (4) unvan katsayısını sahip H1 öğretim üyesi tarafından verilen derslerin 5 saati ilgili öğretim üyesinin mümkünse istemiyorum (1) olarak belirttiği dilimlere atanmış ve buradan elde ettiği memnuniyet puanı $\left(5^{*} 1\right) 5$ olarak tabloya yansıtılmıştır (unvan katsayısı, ağırlıklı toplam hesaplanırken dahil edilmiştir). Aynı şekilde olabilir (2) olarak belirttiği periyotlara 4 ve uygun (3) olarak belirttiği periyotlara 8 saati atanmış ve sırasıyla bu atamalardan $(2 * 4) 8$ ve $(3 * 8) 24$ memnuniyet puanı almıştır. $37(5+8+24)$ olan toplam puan unvan katsayısı (4) ile çarpılarak (4*37) ağırlıklı toplam yani H1 öğretim üyesinin ders çizelgesinden memnuniyet seviyesi 148 olarak hesaplanmıştır.

\section{SONUÇLAR (CONCLUSIONS)}

Akademik sistemler, ülkeden ülkeye, hatta aynı ülkenin akademik sistemi içerisindeki üniversitelerde bile farklılık göstermektedir. $\mathrm{Bu}$ yüzden MBZÇP, literatürde çeşitli kısıtlara ve amaçlara sahip birçok versiyonu ile sıklıkla rastlanan ve halen popülaritesini 
koruyan bir çalışma alanıdır. Bu çalışmada, öncelikle MBZÇP alanında yapılmış çalışmalar taranmış, daha sonra Atatürk Üniversitesi Mühendislik Fakültesi ders çizelgeleme problemi ele alınmıştır. Birçok kısıtı barındıran bu problemde amaç, öğretim üyelerinin unvanlarına göre memnuniyet seviyelerinin enbüyüklenmesidir. Fakültenin fiziksel yapısı nedeni ile fakülte bünyesinde eğitim veren bütün bölümler fakültenin bütün dersliklerini kullanabilmektedir. Yani, her bölüm için ayrı derslik tahsisatı yapılamadığından model, her bölüm için tekrar tekrar çalıştırılarak zaman çizelgesi oluşturulamamaktadır. Bu çalışmada fakülte bünyesindeki tüm bölümlerin aynı anda ele alındığı, aynı zamanda bölümlere ait kısıtların da ihmal edilmediği bütünsel yaklaşıma sahip bir tam sayılı doğrusal programlama modeli önerilmiştir. Önerilen model küçük boyutlu bir problem için çözülmüş ve bütün gereksinimleri karşıladığ 1 görsel bir şekilde gösterilmiştir. Ancak büyük boyutlu bir gerçek hayat problemi için uygun çözüme ulaşılamamıştır. Bu yüzden ders çizelgeleme probleminin çözümünde gevşetme tekniklerinden veya sezgisel tekniklerden yararlanılması önerilebilir.

\section{KAYNAKLAR (REFERENCES)}

1. Cooper, T.B. ve Kingston, J.H., "The complexity of timetable construction problems", Practice and Theory of Automated Timetabling Lecture Notes in Computer Science, Cilt 1153, 281-295, 1996.

2. Alvarez-Valdes, R., Crespo, E., ve Tamarit, J. M., "Design and implementation of a course scheduling system using Tabu Search", European Journal of Operational Research, Cilt 137, 512-523, 2002.

3. Lewis, R., Paechter, B. ve McCollum, B., "Post enrolment based course timetabling: A description of the problem model used for track two of the second international timetabling competition", Cardiff Accounting and Finance Working Papers A2007/3, Cardiff University, Wales. ISSN: 1750-6658, v1.0.

4. Nothegger, C., Mayer, A., Andreas C.A. ve Raidl, G.R., "Solving the post enrolment course timetabling problem by ant colony optimization", Annals of Operations Research, Cilt 194, 325339, 2012.

5. Chiarandini, M., Birattari, M., Socha, K. ve Rossi-Doria, O., "An effective hybrid algorithm for university course timetabling", Journal of Scheduling, Cilt 9, 403-432, 2006.

6. Socha, K., Knowles, J. ve Sampels, M., "A MAX-MIN ant system for the university course timetabling problem", Proceedings of the 3rd International Workshop on Ant Algorithms Lecture Notes in Computer Science, Cilt 2463, 1-13, 2002.

7. Burke, E.K., McCollum, B., Meisels, A., Petrovic, S. ve Qu R., "A graph-based hyper- heuristic for educational timetabling problems", European Journal of Operational Research, Cilt 176, 177-192, 2007.

8. Al-Milli, N., "Hybrid genetic algorithms with great deluge for course timetabling", International Journal of Computer Science and Network Security, Cilt 10, No 4, 283-288, 2010.

9. Kristiansen, S., Sørensen, M. ve Stidsen, T.R., "Elective course planning", European Journal of Operational Research, Cilt 215, 713-720, 2011.

10. Ceschia, S., Di Gaspero, L. ve Schaerf, A., "Design, engineering, and experimental analysis of a simulated annealing approach to the postenrolment course timetabling problem", Computers \& Operations Research, Cilt 39, 1615-1624, 2012.

11. Di Gaspero, L., Schaerf, A. ve McCollum, B., The Second International Timetabling Competition (ICT-2007) Curriculum-based Course Timetabling (Track 3), 2007.

12. .Di Gaspero, L. ve Schaerf, L., "A Multineighbourhood local search with application to course timetabling", Proceedings of the 4 th International Conference On The Practice and Theory of Automated Timetabling (PATAT2002),Lecture Notes in Computer Science, Cilt 2740, Springer-Verlag, 262-275, 2003.

13. Thepphakorn, T., Pongcharoen, P. ve Hicks, C., "An ant colony based timetabling tool", International Journal of Production Economics, Cilt 149, 131-144, 2014.

14. Cacchiani, V., Caprara, A., Roberti, R. ve Toth, P., "A new lower bound for curriculum - based course timetabling", Computers \& Operations Research, Cilt 40, 2466-2477, 2013.

15. Burkea, E.K., Mareceka, J., Parkesa, A.J. ve Rudováb, H., "Decomposition, reformulation and diving in university course timetabling", Computers \& Operations Research, Cilt 37, $582-597,2010$.

16. .Mare cek, J., Course timetabling with integer programming, Doktora tezi, Masaryk University, 2009.

17. Abdullah, S. ve Turabieh, H., "On the use of multi neighbourhood structures within a tabubased memetic approach to university timetabling problems", Information Sciences, Cilt 191, 146$168,2012$.

18. Lü Z. ve Hao J., "Adaptive Tabu Search for course timetabling”, European Journal of Operational Research, Cilt 200, 235-244, 2010.

19. Sánchez-Partida, D., Luis, Martínez-Flores L.J. ve Olivares-Benítez, E., "Modeling and solving a timetabling problem considering time windows and consecutive periods", 5th International Conference on Applied Operational Research, Lizbon-Portugal, Cilt 5, 25-32,2013

20. Bakır, M.A. ve Aksop, C., "A 0-1 integer programming approach to a university 
timetabling problem", Hacettepe Journal of Mathematics and Statistics, Cilt 37, No 1, 41$55,2008$.

21. Cura, T., "Timetabling of faculty lectures using simulated annealing algorithm", İstanbul Ticaret Üniversitesi Fen Bilimleri Dergisi, Cilt 12, Güz 2007/2, 1-20, 2007.

22. Al-Yakoob, S.M. ve Sherali, H.D., "A mixedinteger programming approach to a class timetabling problem: A case study with gender policies and traffic considerations", European Journal of Operational Research, Cilt 180, 1028-1044, 2007.

23. Dimopoulou, M. ve Miliotis, P., “An automated university course timetabling system developed in a distributed environment: A case study", European Journal of Operational Research, Cilt 153, 136-147, 2004.

24. Daskalaki, S., Birbas, T. ve Housos, E., "An integer programming formulation for a case study in university timetabling", European Journal of Operational Research, Cilt 153, 117-135, 2004.

25. Gunawan, A., Ng, K.M. ve Poh, K.L., "Solving the teacher assignment-course scheduling problem by a hybrid algorithm", International Journal of Mechanical, Aerospace, Industrial and Mechatronics Engineering, Cilt 1, No 9, 2007.

26. Tümüklü, M.U., Ders programı hazırlamaya yönelik bir matematiksel programlama yaklaşımı, Yüksek Lisans Tezi, Erciyes Üniversitesi, Sosyal Bilimler Enstitüsü, 2010
27. Gülcü A., Yapay zeka tekniklerinden genetik algoritma ve tabu arama yöntemlerinin eğitim kurumlarının haftalık ders programlarının hazırlanmasında kullanımı, Yüksek Lisans Tezi, Marmara Üniversitesi Fen Bilimleri Enstitüsü, 2006.

28. Basir, N., Ismail, W. ve Norwawi, N.M., "A simulated annealing for tahmidi course timetabling", Procedia Technology, Cilt 11, 437-445, 2013.

29. Miranda, J., Rey, P.A. ve Robles, J.M., "udpSkeduler: A Web architecture based decision support system for course and classroom scheduling”, Decision Support Systems, Cilt 52, 505-513, 2012.

30. Shiau, D., "A hybrid particle swarm optimization for a university course scheduling problem with flexible preferences", Expert Systems with Applications, Cilt 38, 235-248, 2011.

31. Abdennadher, S. ve Marte, M., "University course timetabling using constraint handling rules", Applied Artificial Intelligence, Cilt 14, 311-325, 2000.

32. Henz, M. ve Würtz, J., "Constraint-based timetabling: A case study", Applied Artificial Intelligence, Cilt 10, No 5, 439-453, 1996.

33. Özak, O. ve Saraç, T., "Haftalık ders programının oluşturulması problemi için bir matematiksel model", 9. Endüstri İşletme Mühendisliği Kurultayı, Eskişehir, 77-88, 2013. 
